\title{
Plausible influence of Atlantic Ocean SST anomalies on winter haze in China
}

\author{
Dong Xiao • Ying Li • Shaojia Fan • Renhe Zhang • \\ Jiaren Sun • Yan Wang
}

Received: 25 February 2014 / Accepted: 28 September 2014 /Published online: 11 October 2014

(C) The Author(s) 2014. This article is published with open access at Springerlink.com

\begin{abstract}
The possible influence of Atlantic sea surface temperature (SST) on winter haze days in China at interannual and decadal time scales is investigated using the observed haze-day data from 329 meteorological stations, National Centers for Environmental Prediction-National Centers for Atmospheric Research (NCEP-NCAR) reanalysis, and a SST dataset for 1978-2012. Wintertime haze days in China show robust interannual variations and significant increases over time. The SST anomalies over the North Atlantic from summer to the following winter exhibit a significant in-phase relationship with winter haze days on both decadal and interannual time scales, whereas the anomalous negative-positive SSTs from north to south over the South Atlantic from autumn to the following winter show a significant positive relationship with winter haze days on the interannual time scale. The anomalous warm SST over the North Atlantic, i.e., the positive phase of the Atlantic multidecadal oscillation (AMO), corresponds to the positive phase of the Arctic oscillation (AO). This result implies that a stable mean flow and strong
\end{abstract}

\footnotetext{
D. Xiao $(\bowtie) \cdot$ R. Zhang

Chinese Academy of Meteorological Sciences, Beijing 100081, China

e-mail: xiaodong@cams.cma.gov.cn

Y. Li

National Climate Center, Beijing 100081, China

S. Fan J. Sun

Department of Atmospheric Sciences, Sun Yat-sen University, Guangzhou 510275, China

J. Sun

South China Institute of Environmental Sciences, Ministry of Environmental Protection of PRC, Guangzhou 510655, China

Y. Wang

China Meteorological Administration Training Centre,

Beijing 100081, China
}

westerly anomalies exist over north China. The anomalous dipole pattern in the South Atlantic results in the abnormal southerly airflow in the troposphere over eastern China. Neither the westerly anomalies over north China nor the southerly anomalies over eastern China, which are associated with the North Atlantic and South Atlantic SST anomalies, respectively, are conducive to occurrences of cold air. Consequently, the weakened cold airflow from north of eastern China suppresses the dispersion of pollutants over China and results in above-normal haze days.

\section{Introduction}

Fine particles suspended in the air are atmospheric aerosols with diameters ranging from 0.1 to a few micrometers. The particle sources include the direct emission of fine particles into the atmosphere during the burning of fossil fuels and biomass and other anthropogenic processes, as well as the production of fine particles in the atmosphere from the oxidation and gas-to-particle conversion of gaseous pollutants, such as sulfur dioxide, nitrogen oxides, and volatile organic compounds (Waller et al. 1963; Malm 1992; Kerr 1995). Previous studies have noted the variations in haze (Schichtel et al. 2001; Doyle and Dorling 2002) and the important effects of haze on the climate system (Charlson et al. 1992; Tett et al. 1999; Ramanathan et al. 2005). The increasing urban haze in south and east Asia due to economic expansion has driven a vigorous scientific effort to investigate the importance of aerosol radiative forcing on the Asian monsoon (Chung et al. 2002; Menon et al. 2002; Singh et al. 2005; Lau and Kim 2006; Lau et al. 2006; Liu et al. 2009). Generally, haze is related to nearly every air pollution issue, including adverse health effects, forest and crop damage, building and vehicle emissions, lake and stream contamination, and changes in the Earth's radiation balance (Tie et al. 2009; Wang et al. 2009). 
Meanwhile, scientists have realized the significant effect of climate change on particle concentrations (Liao et al. 2006; Fan et al. 2008; Jacob and Winner 2009; Qu et al. 2010). For particles in China, these studies focus on the effects of the east Asian summer monsoon system on the variations in particle concentrations at multiple time scales (Zhang et al. 2010; Yan et al. 2011; Zhu et al. 2012). However, observations have suggested that urban haze over eastern China is particularly severe in winter ( $\mathrm{Li}$ et al. 1998; Luo et al. 2001; Wu et al. 2005; Wu et al. 2006). Few studies have investigated the characteristics of haze over the entirety of China and its direct relationship with the climate system in winter. Haze is characterized by a specific particle concentration (emission), which is determined by the climate conditions. It is well known that the Atlantic multidecadal oscillation (AMO), North Atlantic oscillation (NAO), and Arctic oscillation (AO) are the dominant climate systems influencing the winter weather in the mid-high latitudes of the Northern Hemisphere, and Atlantic SSTs exhibit a significant relationship with these systems (Wallace and Gutzler 1981; Hurrell 1995; Thompson and Wallace 1998; Czaja and Frankignooul 2002; Li and Bates 2007). Previous studies also documented the possible significant relationship between SST and haze days (Kiehl et al. 2000). Given the above considerations, this study aims to demonstrate the characteristics of winter haze in China in recent decades and to analyze the possible influence of Atlantic SSTs on haze using observational datasets.

\section{Datasets and methods}

Haze is a type of atmospheric phenomenon in which fine aerosol particles are suspended in the air. The particles cause the air to become turbid and result in its visibility distance of less than $10 \mathrm{~km}$. However, visibility can also be reduced by weather phenomena, such as rainfall/snow, dust storms, blowing dust and ash, smoke, and snow flurries. Therefore, days that experience these weather phenomena should be eliminated to quantify haze days. A haze day is defined as a day in which the prevailing visibility is less than $10 \mathrm{~km}$, excluding the days with others weather phenomena that affect visibility. Furthermore, a haze day only occurs if the daily mean relative humidity does not exceed $80 \%$, which is confirmed by the specifications of the surface meteorological observation when the daily mean relative humidity is $80-95 \%$. These criteria for haze days are proposed in the National Standard of Observation Levels of Haze by Wu et al. (2010).

The haze-day dataset used in this paper is obtained from strict quality-controlled Chinese daily observations, which were recently compiled by the National Meteorological Information Center of China. The present analysis is based on seasonal numbers of haze days in winter, which were observed according to the National Standard of Observation
Levels of Haze by Wu et al. (2010). This dataset is widely used in studies of haze days in China (Gao 2008; Shi et al. 2010; Tao et al. 2011; Song et al. 2013; Sun et al. 2013; Ding and Liu 2014; Zhang et al. 2014). The dataset was compiled from 756 stations in China during 1978-2012; 329 stations remained after eliminating the stations with missing values and zeroes.

The SST dataset used in this study is the improved, extended, and reconstructed SST version 3 (Smith and Reynolds 2004). Geopotential height and horizontal wind datasets are derived from the National Centers for Environmental Prediction-National Centers for Atmospheric Research (NCEP-NCAR) reanalysis (Kalnay et al. 1996). The AMO index (Enfield et al. 2001), AO index (Li and Wang 2003a), and NAO index ( $\mathrm{Li}$ and Wang 2003b) are used to assess their relation to the North Atlantic SST anomalies. In addition, the similarity of the South Atlantic Ocean Dipole index (Nnamchi and Li 2011; Nnamchi et al. 2011) to the dipole pattern over the South Atlantic is examined. The main analysis tools applied in this study are correlation analysis and linear regression analysis.

\section{Results}

Figure 1a shows the time series of the seasonal count of haze days averaged over China in winter (November-DecemberJanuary, DJF). The wintertime haze days in China show a significant increasing trend of 2.4 days 10 years $^{-1}$ at the $95 \%$ confidence level during 1978-2012. During 1978-1995, the haze days exhibit a slight decline (not exceeding the $95 \%$ confidence level) and an overlapping moderate interannual variation, with a standard deviation of 1.08 days after removing the trend. The trend in haze days after 1995 tends to be positive (6.6 days 10 years $^{-1}$ during 1995-2012), which is significant at the $99.9 \%$ confidence level. Superimposed interannual variations become intensive afterward, with a standard deviation of 1.99 days. During the period of 20012012 , the haze days display a sharper increase of 9.9 days 10 years $^{-1}$ (significant at the $99.9 \%$ confidence level) than those during 1995-2012; a standard deviation of 1.47 days occurs after removing the trend. Overall, the haze days over east China in winter are exhibiting a faster increase over time.

Such robust interannual variability in the wintertime haze days in China indicates that the climate conditions are more important than the emissions in terms of the interannual variation in haze days considering that emissions from economic expansion are persistent and linearly increasing. On the decadal time scale, the haze days demonstrate a significant increase at a rate of 2.4 days 10 years $^{-1}$ (exceeding the $95 \%$ confidence level; Student's $t$ test). Hereafter, we call the time series of winter haze days averaged over China "HD". 


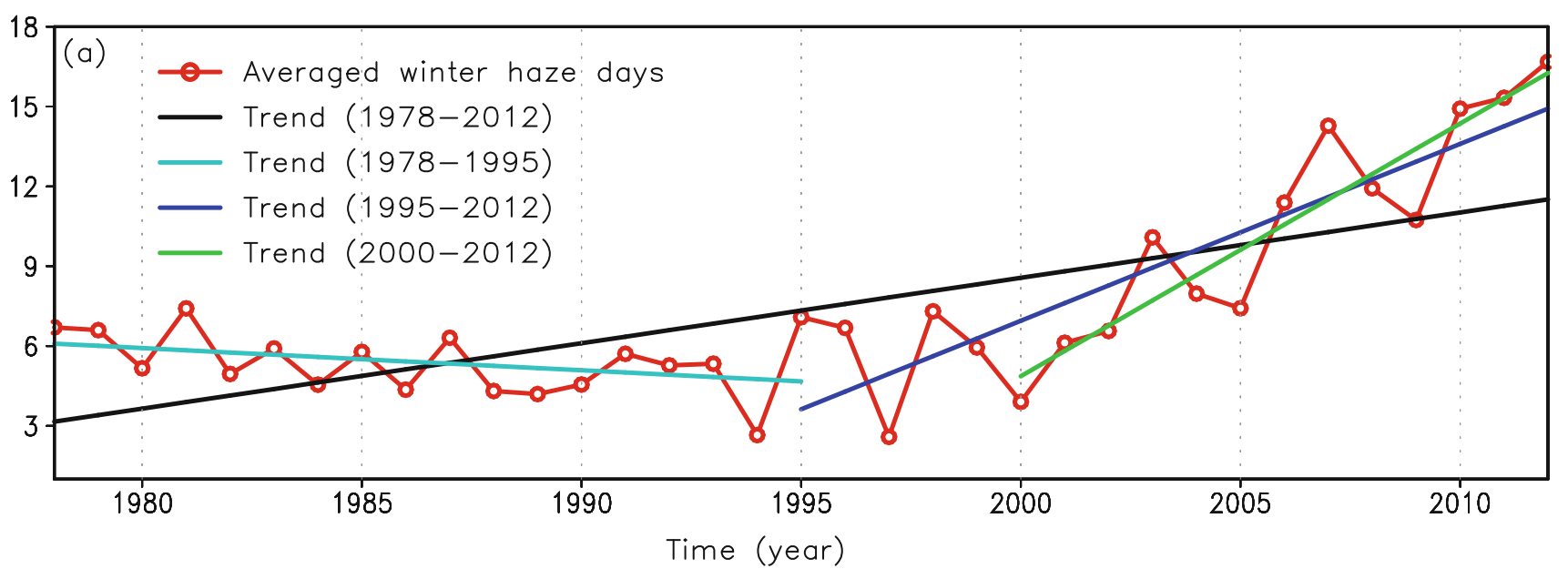

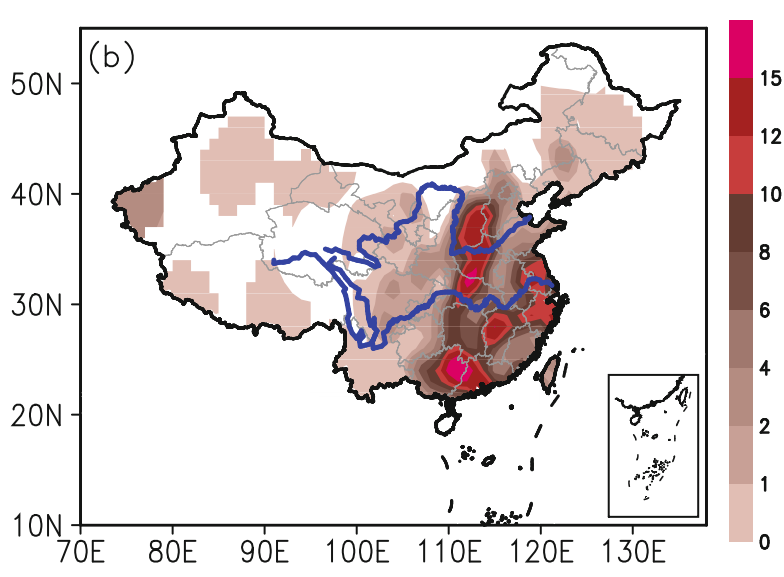

Fig. 1 a Time series of winter haze days averaged over China (red line) and its linear trends during 1978-2012, 1978-1995, 1995-2012, and 2000-2012 (unit, day year ${ }^{-1}$ ), b climatological values in winter haze days, and $\mathbf{c}$ spatial distribution of the linear trend of winter haze days

Figure $1 \mathrm{~b}$ documents the climatological number of winter haze days for 1978-2012. Over most of central and eastern China (south of $40^{\circ} \mathrm{N}$ and east of $108^{\circ} \mathrm{E}$ ), the seasonal haze occurs for more than 4 days. The maximum haze days, 10 days or more, are mainly located in the Pearl River Delta (PRD) in south China, the Yangtze River Delta (YRD) in east China, and the area between $30^{\circ}-40^{\circ} \mathrm{N}$ along $110^{\circ} \mathrm{E}$. Observed haze days at most stations in northeast China and western China amount to fewer than 2 days per season. Figure $1 \mathrm{c}$ demonstrates the spatial distribution of the linear trend in the haze days exceeding the $95 \%$ confidence level. The most intensive increases are mainly located in the PRD and the YRD, with the maximum exceeding 15 days 10 years $^{-1}$. Indeed, the leading empirical orthogonal function (EOF) pattern of anomalous haze days is intensive, increasing tendency in the PRD and YRD (data not shown). By contrast, the haze days decrease over central China, which largely includes the area of $30^{\circ}-40^{\circ} \mathrm{N}$ along $110^{\circ} \mathrm{E}$, although the magnitude of the climatological regional mean is comparable to those in the PRD and YRD. The rate in north China is an increase of 4 over China for 1978-2012 exceeding the $95 \%$ confidence level (unit, day year ${ }^{-1}$ ). The blue curves in $\mathbf{b}$ and $\mathbf{c}$ denote the Yangtze River and Huanghe River

8 days 10 years $^{-1}$, which is much lower than those in the PRD and YRD.

In addition, time series of haze days over four regions (south China, east China, north China, and central China) are displayed in Fig. 2. Winter haze days in south China (including the PRD), which were averaged over 33 stations with significant trends, increased approximately from 0 to 20 days. The upward trend was 7.2 days 10 years $^{-1}$ during 1978-2012, with a much sharper trend during 2002-2012 (Fig. 2a). Interannual variations in haze days over South China have been amplified since the early 1990s, and an extreme value of 30 days occurred in 2007, which is similar to the peak in annual haze days in south China (Ding and Liu 2014). In Fig. 2b, the haze days averaged over 62 stations with significant trends in east China (including the YRD) showing a significant trend of 3.3 days 10 years $^{-1}$, varying from approximately 5 to 15 days (Fig. 2b). Moderate interannual variations and amplified variations occur after 1995. Haze days in north China (Fig. 2c), which are averaged from 24 stations with significant trends, oscillated around 4 days 
Fig. 2 Averaged winter haze days over a south China (100$120^{\circ}$ E, $\left.15-25^{\circ} \mathrm{N}\right)$, b east China $\left(113-125^{\circ} \mathrm{E}, 25-35^{\circ} \mathrm{N}\right)$, c north China $\left(113-130^{\circ} \mathrm{E}, 35-45^{\circ} \mathrm{N}\right)$, and $\mathbf{d}$ central China $\left(100-113^{\circ} \mathrm{E}\right.$, $\left.25-40^{\circ} \mathrm{N}\right)$. Haze days averaged from the above regions are based on the significant trend stations in Fig. 1c. Station numbers in each region and trends of each time series are displayed at the top of each panel. The unit of the ordinate is day. All the trends are significant at the $95 \%$ confidence level (a) South China

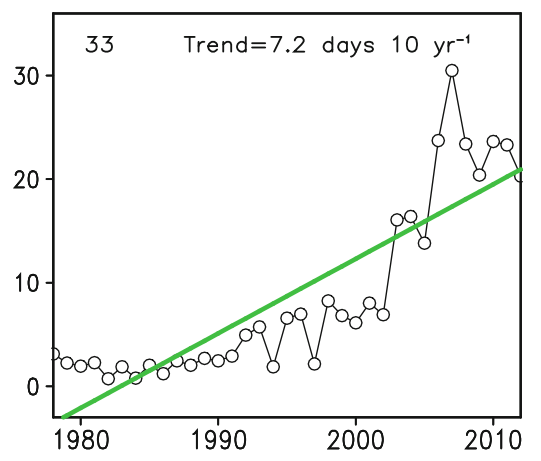

(c) North China

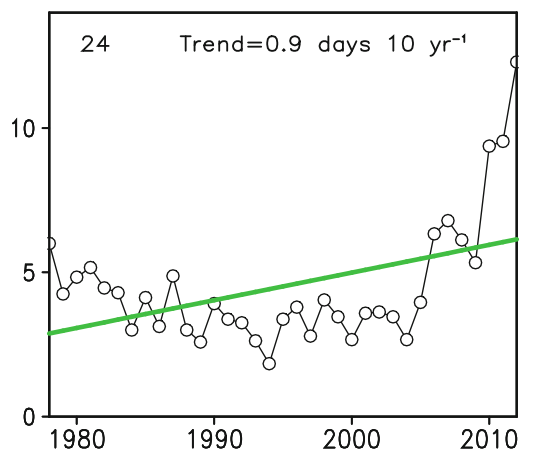

(b) East China

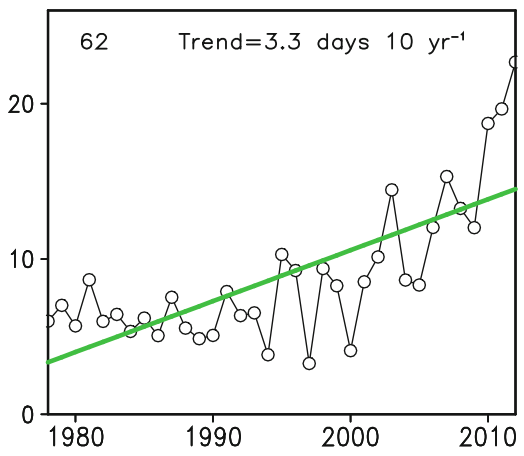

(d) Central China

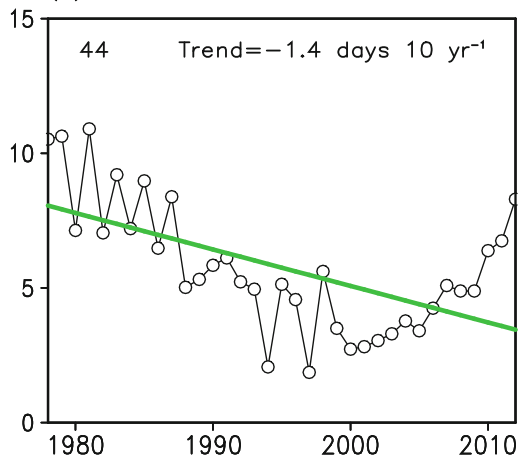

during 1978-2005 then increased quickly after 2005 and reached 13 days in 2012. Moreover, the variation in the haze days in Beijing (northern China) is similar to that in north China. Specifically, a faster increase occurs compared with north China during 1978-2005; the number reached 40 days in 2012 and accounted for four ninths of the winter (Figure not shown). Haze days in central China (Fig. 2d), which are averaged from 44 stations with significant trends, generally show a decrease of -1.4 days 10 years $^{-1}$ and vary from 11 to 2 days. However, haze days in central China display a decline during 1978-2000 and a sharper increase afterward such that haze days in 2012 are generally equal to the averaged value in the 1980s. Overall, except for the relatively slight decline over central China, other regions in China show an obvious increase in haze days.

Although the increasing haze days over north, east, and south China may be a consequence of the increase in fossil fuel burning due to economic expansion in the three regions, the magnitude of particle concentrations is not the sole factor that determines haze days. The increasing haze days in China is inevitably accompanied by the meteorological conditions that are unfavorable to pollutant dispersion. As mentioned, the dominating winter climate systems in the Northern Hemisphere are the AMO, NAO, and AO, which are significantly influenced by the SST anomalies over the Atlantic. Given the considerations, we focus on the possible impacts of Atlantic SST anomalies on winter haze days in China and the associated physical processes.
Figure 3 depicts the spatial distribution of the correlation coefficients between Atlantic SST in the previous summer (June-July-August, JJA), previous autumn (SeptemberOctober-November, SON), and the current winter (DJF) and the HD. Note that the SSTs over the tropical North Atlantic and the Atlantic north of $50^{\circ} \mathrm{N}$ show significant positive correlations with the HD from the previous summer to the current winter. Moreover, the HD is also associated with a dipole pattern in the SST over the South Atlantic from the previous autumn to the current winter that is characterized by significant positive SST anomalies south of $30^{\circ} \mathrm{S}$ in the South Atlantic and negative SST anomalies north of $30^{\circ} \mathrm{S}$ in the South Atlantic. To achieve a better understanding of the relationship between Atlantic SSTs and the HD, we define a North Atlantic SST index (NAI) using a sum of the normalized SSTs averaged over the two domains of $50^{\circ}-70^{\circ} \mathrm{N}, 60^{\circ}-$ $30^{\circ} \mathrm{W}$ and $10^{\circ}-20^{\circ} \mathrm{N}, 70^{\circ}-55^{\circ} \mathrm{W}$ in the previous summer and a South Atlantic SST index (SAI) using the remaining normalized SSTs over the area of $50^{\circ}-30^{\circ} \mathrm{S}, 60^{\circ}-20^{\circ} \mathrm{W}$ minus the normalized SSTs over the area of $30^{\circ}-10^{\circ} \mathrm{S}, 30^{\circ}-10^{\circ} \mathrm{W}$ in the previous autumn. These areas are chosen based on the significant relationship between SSTs and the HD.

Interestingly, significant correlations between the $\mathrm{HD}$ and SST in Fig. 3 are mainly confined to the northernmost and southernmost parts of the North Atlantic. This correlation pattern is similar to the AMO pattern. Nevertheless, the correlations between the NAI in JJA and the AMO index (Enfield et al. 2001) in JJA, SON, and DJF are 0.89, 0.86, and 0.70, 
Fig. 3 Spatial distribution of correlation coefficients between the HD and Atlantic SST in a the previous summer, $\mathbf{b}$ the previous autumn, and $\mathbf{c}$ the current winter. The green (blue) shadings denote the positive (negative) correlation coefficients exceeding the $95 \%$ confidence level (a) JJA

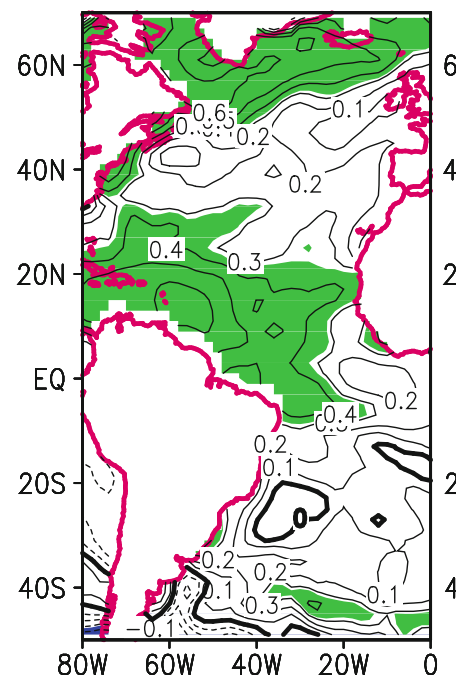

(b) SON

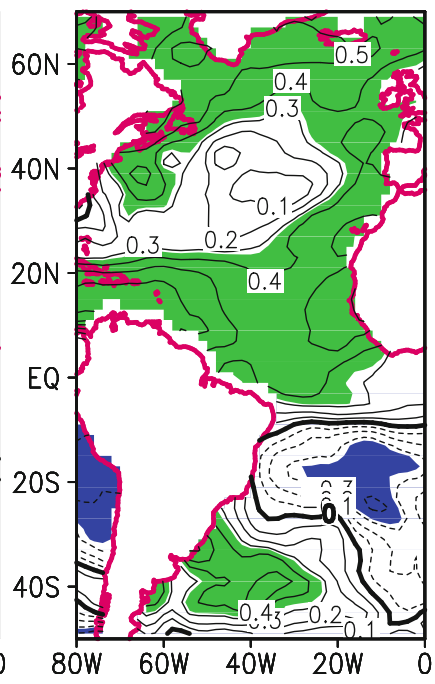

(c) DJF

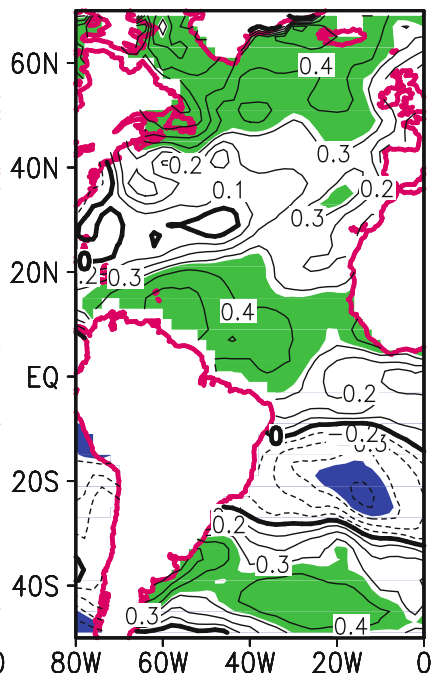

respectively. The NAI and AMO reveal similar climate impacts, and the NAI performs better. Essentially, the NAI and AMO index (Enfield et al. 2001) both represent the variation in the AMO. Therefore, we used the NAI to represent the AMO index in the remainder of the study. Both the AMO and HD experience a phase transition from negative to positive around 1995. Specifically, a high correlation coefficient between the HD and AMO indicates that the phase transition in the AMO provides a decadal background to the variation in the HD. Moreover, significant correlations between the HD and SST in Fig. 3 show a dipole pattern over the South Atlantic Ocean. We compare this dipole with the South Atlantic Ocean Dipole defined by Nnamchi et al. (Nnamchi and Li 2011; Nnamchi et al. 2011). The South Atlantic Ocean Dipole defined by Nnamchi et al. showed positive anomalies over the northeastern South Atlantic, with a center at $5^{\circ} \mathrm{S}, 10^{\circ}$ $\mathrm{W}$ and negative anomalies over the southwestern South Atlantic, with a center at $30^{\circ} \mathrm{S}, 30^{\circ} \mathrm{W}$. The dipole in Fig. $3 \mathrm{~b}$ of this study depicted negative anomalies over the central South Atlantic, with a center at $20^{\circ} \mathrm{S}, 10^{\circ} \mathrm{W}$ and positive anomalies over the southwestern South Atlantic, with a center at $40^{\circ} \mathrm{S}, 40^{\circ} \mathrm{W}$. Obviously, the anomaly centers differ. In addition, the correlation coefficient between the index of the South Atlantic Ocean Dipole, defined by Nnamchi et al., and the SAI in this study is -0.12 , which is not significant at the $90 \%$ confidence level. Therefore, these dipoles may not be the same from SON to DJF.

Figure 4a shows the time series of the AMO and HD. Overall, the AMO shows similar decadal variations to those in the HD, particularly for the intensive increase after 1995. The AMO is significantly associated with the anomalous positive haze days with a correlation coefficient exceeding the $99 \%$ confidence level $(r=0.67)$. The in-phase percentage between the AMO and HD is $80 \%$ for 1978-2012. The AMO index in summer exhibits a significant relationship with those in autumn and winter ( $r=0.92$ between the summer SST and the autumn SST and $r=0.89$ between the autumn SST and the winter SST). Namely, the warm North Atlantic SST anomalies can persist into autumn and winter; this explains the significant positive correlation between the HD and the AMO from the previous summer to the current winter. Actually, the relationship between the AMO and $\mathrm{HD}$ at the interannual time scale is also significant ( $r=0.47$ between the detrended AMO and detrended HD, exceeding the $95 \%$ confidence level). Thus, the AMO is highly correlated to the HD at both decadal and interannual time scales.

Figure $4 \mathrm{~b}$ illustrates the regression of the geopotential heights at $500 \mathrm{hPa}$ on the HD. The intensely negative geopotential height anomalies occur north of $60^{\circ} \mathrm{N}$ over the Eurasian landmass and Pacific Ocean, whereas positive anomalies occur south of $60^{\circ} \mathrm{N}$ in the Northern Hemisphere, with significant positive anomalies located around northwestern Africa, the zone from the Arabian Sea to the Bay of Bengal, north China, the tropical west Pacific, and the northern central Pacific. Overall, such a meridional structure of the geopotential height anomalies generally indicates the positive phase of the AO. The anomalous geopotential heights associated with the AMO are similar to those of the HD (Fig. 4c), with negative anomalies north of $60^{\circ} \mathrm{N}$ over the Eurasian landmass and Atlantic Ocean and positive anomalies south of $60^{\circ} \mathrm{N}$ over the Northern Hemisphere. The significant positive anomalies around north China extend southwestward to the areas of the Arabian Peninsula, Arabian Sea, Indian continent, Tibetan plateau, and mid-latitude China. Additionally, the anomalies over the subtropical North Atlantic are significantly positive. Compared with the anomalies associated with the HD, the anomalous geopotential heights associated with the AMO exhibit a more obvious positive AO pattern, with a correlation coefficient of 0.36 between the AMO and winter AO (significant at the $95 \%$ confidence level). Actually, the 


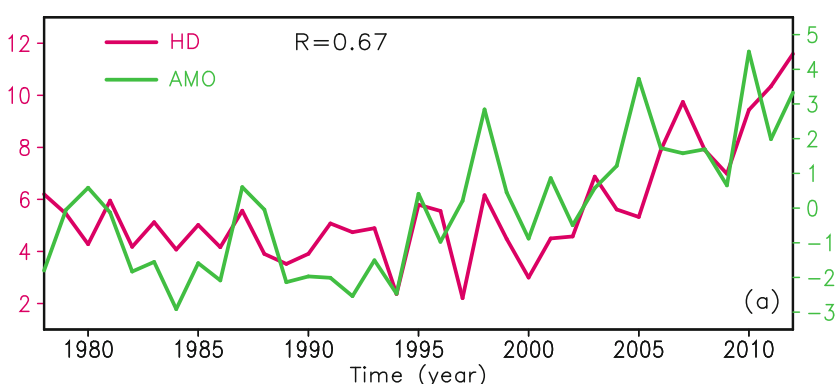

Reg. of $500 \mathrm{hPa}$ height on $\mathrm{HD}$ Reg. of $500 \mathrm{hPa}$ height on $\mathrm{AMO}$
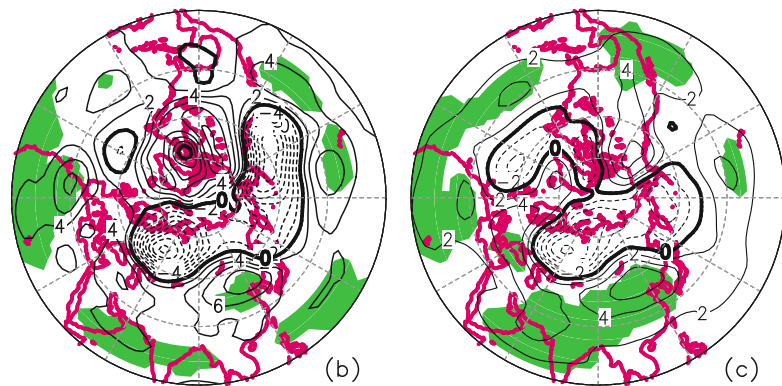

Fig. 4 Time series of a the HD (red line; unit, day) and the AMO (green line). Regression of the geopotential height in winter at $500 \mathrm{hPa} \mathbf{b}$ on the $\mathrm{HD}$ (unit, gpm day ${ }^{-1}$ ) and $\mathbf{c}$ on the AMO (unit, gpm). Green shadings in $\mathbf{b}$ and $\mathbf{c}$ denote the linear regression coefficients exceeding the $95 \%$ confidence level

$\mathrm{AO}$ in winter has been documented to be significantly related to the Atlantic SST anomalies in the previous summer (Czaja and Frankignooul 2002). The results in this study and previous studies show that the warm phase of the AMO could induce a positive phase of the $\mathrm{AO}$ in the following winter. A positive phase of the AO implies a more stable basic flow in winter, which is not conducive to air exchanges between the high and low latitudes or to the outbreak of cold air north of China (Gong et al. 2001). Overall, positive anomalies of the $\mathrm{AO}$ are not conducive for dispersing air pollutants; therefore, more frequent haze events occur in China.

Figure 5a shows the time series of the normalized SAI, the $\mathrm{HD}$, and the detrended HD. Note that the variations in the HD and SAI are similar at the interannual time scale, although the SAI does not exhibit an increase, in contrast to the HD. The correlation coefficient between the detrended HD and SAI is 0.64 , exceeding the $99 \%$ confidence level. The in-phase percentage between the detrended HD and SAI is $77 \%$ for 1978-2012; this percentage is important for predicting haze days in winter. Namely, if the SST anomalies over the South Atlantic show a positive-negative dipole from south to north in the previous autumn, there is a $77 \%$ probability of the occurrence of above-normal haze days in China in winter. As depicted in Fig. 4, the SST dipole pattern in the South Atlantic in the autumn can persist into the winter, with a correlation coefficient of 0.68 (exceeding the $99.9 \%$ confidence level).

Figure $5 \mathrm{~b}$ exhibits the regression of the horizontal winds at $850 \mathrm{hPa}$ on the detrended HD. Clearly, the above-normal haze
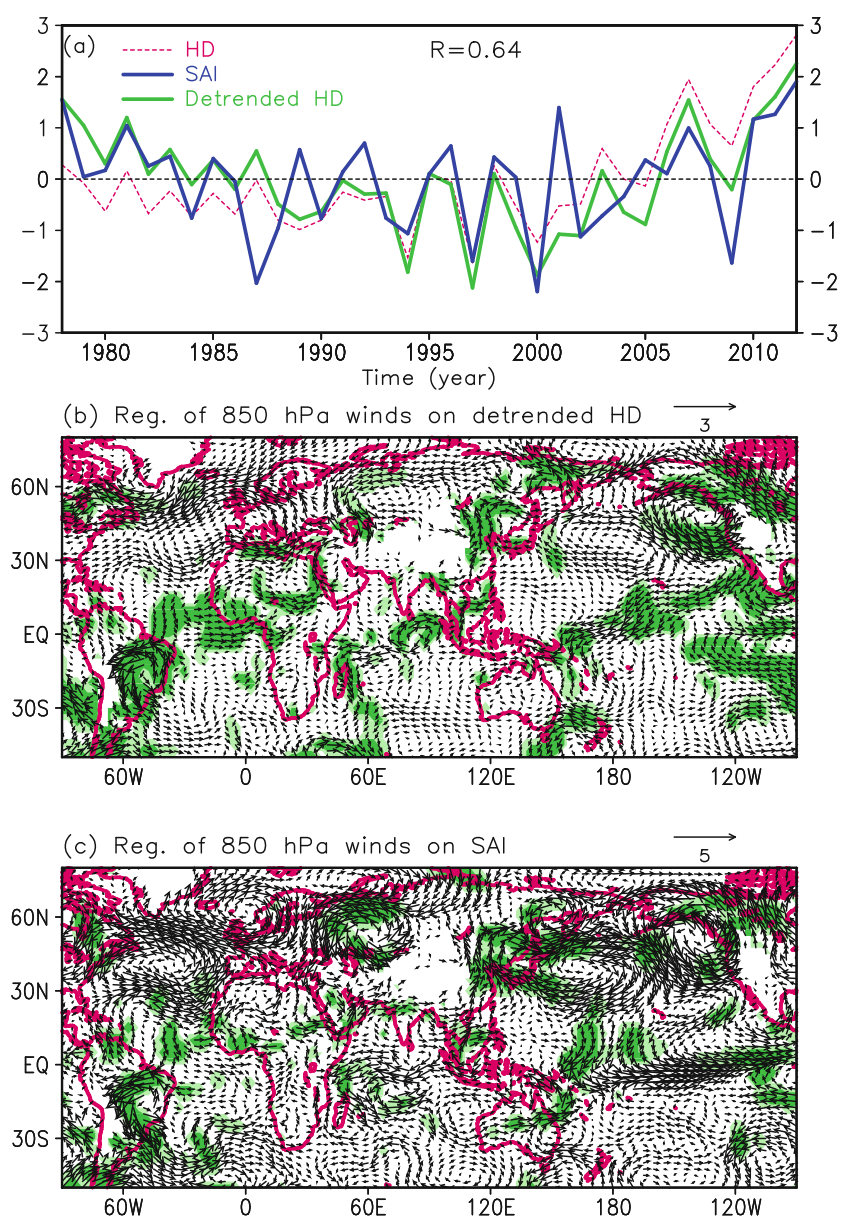

Fig. 5 Time series of a the normalized HD (dashed red line), detrended HD (solid green line), and SAI (solid blue line). Regression of the horizontal winds in winter at $850 \mathrm{hPa}$ on $\mathbf{b}$ the detrended HD (unit, $\mathrm{m} \mathrm{s}^{-1}$ day $^{-1}$ ) and on $\mathbf{c} \mathrm{SAI}$ (unit, $\mathrm{m} \mathrm{s}^{-1}$ ). Dark (shallow) green shadings denote the liner regression coefficients exceeding $95 \%$ (90\%) confidence level

days are associated with anomalous southerly airflow over eastern China and a westerly airflow over southern China. Specifically, the cold northerly airflow over eastern China is weaker than the climatological pattern and is unfavorable for the diffusion of fine particles; as a result, above-normal haze days occur in China. The anomalous southerly airflow over eastern China and the westerly airflow over southern China may be a consequence of the three large-scale circulation anomalies shown in Figure 5c. The first anomalous circulation is the abnormal wave train from the Atlantic moving eastward to Eurasia. This circulation is associated with three abnormal cyclonic circulation centers located over the subtropical South Atlantic, mid-latitude North Atlantic, and west Siberia and four abnormal anticyclonic circulation centers located over the western South Atlantic near $30^{\circ} \mathrm{S}$, south of $30^{\circ} \mathrm{N}$ in the North Atlantic, east Europe, and northeast China. The second abnormal circulation is the anomalous northeasterly airflow over the tropical central Pacific, accompanied by an abnormal anticyclonic circulation over the North Pacific basin. These two 
circulation anomalies correspond to the abnormal southerly airflow over eastern China. Additionally, the anomalous westerly airflow from the tropical Atlantic to Africa-Indian Oceansouthern China and the two abnormal anticyclonic circulations across the tropical Indian Ocean may be related to the significant westerly airflow anomalies over southern China. Previous studies documented the relationship and physical processes linking the South Atlantic SST and the aforementioned circulation anomalies (Xie and Tanimoto 1998; Haarsma et al. 2003; Robertson et al. 2003; Rong et al. 2010). These wave trains found in the anomalous horizontal winds that accompany SAI in the previous autumn (Fig. 5c) are similar to those associated with the HD (Fig. 5b). Actually, the abnormally low tropospheric horizontal winds over east Asia associated with the HD or the SAI can also be found in the middle and upper troposphere, i.e., a deep quasi-barotropic structure is present (not shown). Namely, the SST dipole pattern over the South Atlantic in the previous autumn may trigger favorable meteorological conditions for winter haze in China.

Both the AMO and SAI influence the variations in the haze days in China. Are the influences of the North Atlantic independent of the influences of the South Atlantic? The SAI does not show obvious linear trends during 1978-2012. Therefore, the high correlation coefficient between the SAI and HD implies that the influence of the SAI on the winter haze days in China mainly occurs at the interannual time scale. The AMO exhibits an obvious linear trend in this period. The correlation coefficient between the (detrended) AMO and HD over China is (0.47) 0.67, which indicates the AMO influence on the HD at both the decadal and interannual time scales. In other words, the influences of the SAI and AMO on the HD are independent at the decadal time scale. Furthermore, the partial correlation coefficient between the SAI and HD, except for the AMO influence, is 0.51 , which is less than the correlation coefficient between the SAI and HD (0.64). These results imply that the influence of the SAI on the $\mathrm{HD}$ at the interannual time scale is larger than that of the AMO. Furthermore, the influences of the SAI and AMO on the HD are not independent at the interannual time scale.

\section{Summary and discussion}

The winter haze days averaged over China experienced robust interannual variations and an obvious increase during 19782012 , with a rate of 2.4 days 10 years $^{-1}$ and a range from approximately 6 to 17 days. The trends in the wintertime haze days in China are increasing over time. The variation in the haze days reveals regional features. The haze days over south, east, and north China all showed increases that were significant at the $95 \%$ confidence level. However, central China generally exhibited decreases during 1978-2012 and an increase after 2000.

This study reveals the climatic cause of the interannual and decadal variations in the winter haze days in China. The wintertime haze days are highly related to the SST over the Atlantic Ocean. Specifically, the correlation coefficient between the HD and SST indicates that an AMO pattern exists in the North Atlantic and a dipole pattern exists in the South Atlantic, in contrast to the conditions proposed by Nnamchi et al. The AMO exhibits a significant in-phase relationship with haze days at the decadal and interannual time scales. The increasing summer AMO significantly impacted the AO in winter. As a result, the atmospheric anomalies associated with the AMO indicated a positive phase of the AO anomalies; these conditions correspond to stable mean flow and less frequent cold air events in east China. These situations are not conducive for dispersing air pollutants. The abnormal SST dipole pattern over the South Atlantic was significantly related to the haze days at the interannual time scale. Anomalous atmospheric circulation associated with the SAI revealed quasi-barotropic anticyclones over east China. The abnormal SST dipole pattern over the South Atlantic influenced the atmospheric anomalies over east China via the quasibarotropic wave trains from the Atlantic to Eurasia and the abnormal northeasterly airflow over the North Pacific basin; the pattern also influenced the abnormal westerly airflow in the troposphere from the tropical Atlantic to the Arabian Sea and south of China. The southerly flow anomalies over east China were not conducive to cold air outbreaks or air pollutant dispersion; thus, a high frequency of haze days occurred.

The increasing emissions due to economic expansion are considered a necessary factor for increasing the winter haze days in China. Moreover, the North Atlantic SST also plays an important role in the winter haze-day trends in China. However, neither the increasing emissions nor the stable climate are sufficient conditions; the joint effects of these conditions are actually necessary for the occurrence of haze in China. The fine particles that compose haze are mainly sulfates and nitrates. However, the emission of these fine particles in China in recent decades has not been well documented or precisely estimated. Presently, it is difficult to evaluate the relative contributions of increasing emissions and decadal climatic trends influenced by the AMO to winter haze days in China. The contribution of emissions related to economic expansion to the increasing haze days in China will be the subject of a future study once sulfate and nitrate emission data with adequate spatial and temporal resolutions are released. Furthermore, the contributions of increasing emissions and decadal climatic patterns should be further studied using the atmospheric chemical transport model.

The HD exhibits obvious interannual variations during the persistent increasing emissions over China. Therefore, the interannual variation in winter haze days in China may be 
dominated by the dipole North Atlantic to South Atlantic SSTs. Furthermore, the high in-phase percentage (77 \%) between the detrended HD and the South Atlantic SST dipole in autumn implies that the South Atlantic SST dipole could be used as an excellent predictor of the interannual variation in winter haze days in China. The mechanism for which the South Atlantic SST dipole in autumn influences China's winter climate is unknown. Three possible wave trains that connect the South Atlantic SST dipole and China's winter climate have not been statistically evaluated in terms of their relative importance. Moreover, the North Atlantic SSTs also influenced China's winter climate at the interannual time scale. Therefore, the relative importance of the three possible wave trains resulting from the South Atlantic SSTs and the contribution of the North Atlantic SST needs to be distinguished by employing climate models in future studies.

Acknowledgments We would like to thank Dr. Bingyi Wu, Zhiyan Zuo, and two anonymous reviewers for their help. This study was jointly supported by the National Program on Key Basic Research Project of China (2011CB403403), National Natural Science Foundation of China (41405078, 41205059, and 41375092), and the International S\&T Cooperation Project of the Ministry of Science and Technology of China (2009DFA21430).

Open Access This article is distributed under the terms of the Creative Commons Attribution License which permits any use, distribution, and reproduction in any medium, provided the original author(s) and the source are credited.

\section{References}

Charlson R, Schwartz S, Hales J et al (1992) Climate forcing by anthropogenic aerosols. Science 255:423-430

Chung C, Ramanathan V, Kieh J (2002) Effect of the South Asian absorbing haze on the Northeast monsoon and surface-air heat exchange. J Clim 15:2462-2476

Czaja A, Frankignooul C (2002) Observed impact of Atlantic SST anomalies on the North Atlantic Oscillation. J Clim 15:606-623

Ding YH, Liu YJ (2014) Analysis of long-term variations of fog and haze in China in recent 50 years and their relations with atmospheric humidity. Sci China Earth Sci 57:36-46

Doyle M, Dorling S (2002) Visibility trends in the UK 1950-1997. Atmos Environ 36:3161-3172

Enfield DB, Mestas-Nunez AM, Trimble PJ (2001) The Atlantic multidecadal oscillation and its relation to rainfall and river flows in the continental US. Geophys Res Lett 28:2077-2080

Fan S, Wang B, Tesche M et al (2008) Meteorological conditions and structures of atmospheric boundary layer in October 2004 over Pearl River Delta area. Atmos Environ 42:6174-6186

Gao G (2008) The climatic characteristics and change of haze days over China during 1961-2005 (in Chinese). Acta Geograph Sin 63:762768

Gong D, Wang S, Zhu J (2001) East Asian winter monsoon and Arctic Oscillation. Geophys Res Lett 28:2073-2076

Haarsma RJ, Campos EJD, Molteni F (2003) Atmospheric response to South Atlantic SST dipole. Geophys Res Lett 30:1864

Hurrell JW (1995) Decadal trends in the North Atlantic Oscillation: regional temperatures and precipitation. Science 269:676-679
Jacob D, Winner D (2009) Effect of climate change on air quality. Atmos Environ 43:51-63

Kalnay E et al (1996) The NCEP/NCAR 40-year reanalysis project. Bull Am Meteorol Soc 77:437-471

Kerr R (1995) Climate study unveils climate cooling caused by pollutant haze. Science 268:802

Kiehl J, Hack J, Ramanathan V (2000) The roles of absorbing aerosols in climate simulation. Eos Trans Ame Geophys Union 81:48

Lau K-M, Kim K-M (2006) Observational relationships between aerosol and Asian monsoon rainfall and circulation. Geophys Res Lett 33: L21810

Lau K-M, Kim M-K, Kim K-M (2006) Asian monsoon anomalies induced by aerosol direct effects. Clim Dyn 26:855-864

Li SL, Bates G (2007) Influence of the Atlantic Multidecadal Oscillation (AMO) on the winter climate of East China. Adv Atmos Sci 24: 126-135

Li JP, Wang JXL (2003a) A modified zonal index and its physical sense. Geophys Res Lett 30:1632

Li JP, Wang JXL (2003b) A new North Atlantic Oscillation index and its variability. Adv Atmos Sci 20:661-676

Li X, Li W, Zhou X (1998) Analysis of the solar radiation variation of China in recent 30 years. Q J Appl Meteorol 9:24-30

Liao H, Chen W-T, Seinfeld J (2006) Role of climate change in global predictions of future tropospheric ozone and aerosols. J Geophys Res 111:D12304

Liu Y, Sun JR, Yang B (2009) The effects of black carbon and sulphate aerosols in China regions on East Asia monsoons. Tellus 61B:642656

Luo Y, Lu D, Zhou X et al (2001) Characteristics of the spatial distribution and yearly variation of aerosol optical depth over China in last 30 years. J Geophys Res 106:14501-14513

Malm W (1992) Characteristics and origins of haze in the continental United States. Earth Sci Rev 33:1-36

Menon S, Hansen J, Nazarenko L et al (2002) Climate effects of black carbon aerosols in China and India. Science 297:2250 2253

Nnamchi HC, Li J (2011) Influence of the South Atlantic Ocean dipole on West African summer precipitation. J Clim 24:1184-1197

Nnamchi HC, Li J, Anyadike RNC (2011) Does a dipole mode really exist in the South Atlantic Ocean? J Geophys Res 116:D15104. doi: 10.1029/2010jd015579

Qu W, Arimoto R, Zhang X et al (2010) Spatial distribution and interannual variation of surface PM10 concentrations over eighty-six Chinese cities. Atmos Chem Phys 10:5641-5662

Ramanathan V, Chung C, Kim D et al (2005) Atmospheric brown clouds: impacts on South Asian climate and hydrological cycle. Proc Natl Acad Sci U S A 102:5326

Robertson A, Farrara JD, Mechoso CR (2003) Simulations of the atmospheric response to South Atlantic sea surface temperature anomalies. J Clim 16:2540-2550

Rong XY, Zhang RH, Li T (2010) Impact of Atlantic sea surface temperature anomalies on Indo-East Asian summer monsoon-ENSO relationship. Chin Sci Bull 55:2458-2468

Schichtel BA, Husar RB, Falke SR et al (2001) Haze trends over the United States, 1980-1995. Atmos Environ 35:5205-5210

Shi J, Cui L, He Q (2010) The changes and causes of fog and haze days in eastern China (in Chinese). Acta Geograph Sin 65:533541

Singh R, Tare V, Tripathi S (2005) Aerosols, clouds and monsoon. Curr Sci 88:1366-1368

Smith T, Reynolds R (2004) Improved extended reconstruction of SST (1854-1997). J Clim 17:2466-2477

Song LC, Gao R, Li Y et al (2013) Analysis of China's haze days in winter half year and climatic background during 1961-2012 (in Chinese). Adv Clim Chang Res 9:313-318 
Sun Y, Ma Z, Niu T et al (2013) Characteristics of climate change with respect to fog days and haze days in China in the past 40 years (in Chinese). Clim Environ Res 18:397-406

Tao Y, Duan X, Duan CC (2011) The change characteristics of fog in Yunnan during the nearly 50 years (in Chinese). J Yunnan Univ (Nat Sci) 33:308-316

Tett S, Stott P, Allen M et al (1999) Causes of twentieth century temperature change near the earth's surface. Nature 399:569-572

Thompson DWJ, Wallace JM (1998) The Arctic Oscillation signature in the wintertime geopotential height and temperature fields. Geophys Res Lett 25:1297-1300

Tie X, Wu D, Brasseur G (2009) Lung cancer mortality and exposure to atmospheric aerosol particles in Guangzhou, China. Atmos Environ 43:2375-2377

Wallace JM, Gutzler DS (1981) Teleconnections in the geopotential height field during the Northern Hemisphere winter. Mon Weather Rev 109:784-812

Waller R, Brooks A, Carwright J (1963) An electron microscope study of particles in town air. Int J Air Water Pollut 7:779-786

Wang K, Dickinson R, Liang S (2009) Clear sky visibility has decreased over land globally from 1973 to 2007 . Science 323:1468-1470
Wu D, Tie X, Li C et al (2005) An extremely low visibility event over the Guangzhou region: a case study. Atmos Environ 39: $6568-6577$

Wu D, Tie X, Deng X (2006) Chemical characterizations of soluble aerosols in southern China. Chemosphere 64:749-757

Wu D, Tang SW, Deng XJ et al (2010) Observation and forecasting levels of haze (in Chinese). Beijing, China, Meteorological Press, p 5

Xie S-P, Tanimoto Y (1998) A pan-Atlantic decadal climate oscillation. Geophys Res Lett 25:2185-2188

Yan L, Liu X, Yang P et al (2011) Study of the impact of summer monsoon circulation on spatial distribution of aerosol in East Asia based on numerical simulations. J Appl Meteorol 50:2270-2282

Zhang L, Liao H, Li J (2010) Impacts of Asian summer monsoon on seasonal and interannual variations of aerosols over eastern China. $\mathrm{J}$ Geophys Res 115:D00k05

Zhang RH, Li Q, Zhang RN (2014) Meteorological conditions for the persistent severe fog and haze event over eastern China in January 2013. Sci China Earth Sci 57:26-35

Zhu J, Liao H, Li J (2012) Increases in aerosol concentrations over eastern China due to the decadal-scale weakening of the East Asian summer monsoon. Geophys Res Lett 39:L09809 